\title{
Acute optic neuritis: its clinical features and their relation to prognosis for recovery of vision
}

\author{
W. G. BRADLEY AND C. W. M. WHITTY \\ From the Department of Neurology, United Oxford Hospitals
}

The clinical syndrome of acute optic neuritis has been known for many years though its causes are still uncertain. McAlpine, Lumsden, and Acheson (1965) state that the only common cause of unilateral optic neuritis is multiple sclerosis, but many others have been suggested (Woods and Rowland, 1931; Benedict, 1933; Carroll, 1952; Walsh, 1957; Hierons and Lyle, 1959; Kennedy and Carroll, 1960; and McAlpine et al., 1965, Björkenheim, 1966). Despite this possible diversity of causes the syndrome usually has a stereotyped clinical picture. Blurring of vision in one, or more rarely both, eyes develops rapidly and usually increases over a few days, sometimes to complete loss of vision. Central vision is particularly affected. Pain in and around the affected eye, exaggerated by eye movement, is common. In any one attack final recovery of sight is usually good.

In the present paper the degree of recovery of vision, its time course, and the features of the acute attack which may indicate the prognosis are considered in a series of 73 cases seen in the Department of Neurology, United Oxford Hospitals, between 1946 and 1966. The association between optic neuritis and multiple sclerosis is reviewed in another paper (Bradley and Whitty, 1967).

The definition of acute optic neuritis is a clinical one. For inclusion in the present series we required the acute onset of blurred vision in one or both eyes, with a central, paracentral, or centrocaecal scotoma, which had no demonstrable local cause such as intracranial tumour, arterial obstruction, or retinal lesion and with no other preexisting or coexisting neurological signs. We included cases with and without papilloedema, since the distinction is at times tenuous and the course similar in each group.

\section{MATERIAL}

The case histories of 123 patients initially diagnosed as acute optic neuritis were examined. Fifty cases were excluded : 27 because of insufficient information; 10 with another later established diagnosis; seven with preexisting neurological disease (see Table I); and six with a typical history but an atypical field defect. These last six and a further six whose visual
TABLE I

DIAGNOSTIC CATEGORIES IN THE INITIAL SURVEY

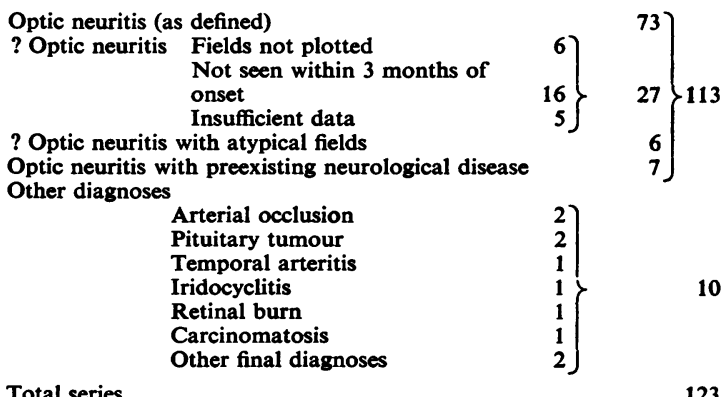

fields had not been charted were analysed separately and will be mentioned below. Seventy-three patients were left for our main analysis, 52 unilateral and 21 bilateral at some time (Table II). Three patients were known to have died, four had emigrated, and 13 could not be traced. The remaining 53 were re-examined; the period of follow-up ranged from six months to 20 years, the average being $7 \cdot 4$ years.

\section{FINDINGS}

In addition to analysing the data on the whole group of 73 patients, subgroups shown in Table II were separately analysed. No significant differences were detected and these subgroups will not be mentioned again.

\section{TABLE II}

FREQUENCY OF UNILATERAL AND BILATERAL OPTIC NEURITIS

\begin{tabular}{lr} 
& No. \\
\hline Unilateral & $51(71 \%)$ \\
Bilaterul at same time & $5(7 \%)$ \\
Bilateral, less than 3 months' interval & $9(12 \%)$ \\
Bilateral, more than 3 months' interval & $7(10 \%)$ \\
Totals & $73(100 \%)$
\end{tabular}

SEX Females comprised nearly two-thirds of the whole series, the proportion being 46 to 27 . 


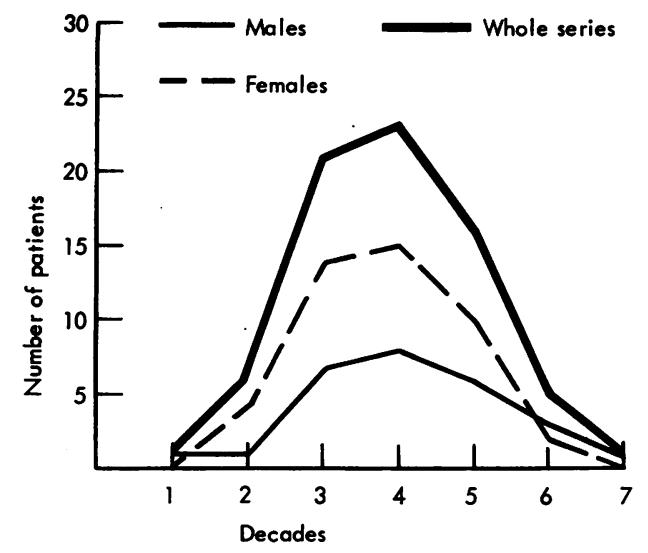

FIG. 1. Age structure of the whole series of 73 cases of optic neuritis, and of males and females separately.

AGE Of the 73 cases, $82 \%$ occurred between the ages of 20 and 50 years, though one case occurred at the age of 9 and one at the age of 65 years. The same age structure appeared in males and females (Fig. 1).

TIME OF- ONSET The annual incidence remained approximately constant throughout the 20-year period in which cases were seen, and there was no evidence of a change in referral pattern during the period. Analysis of the month of onset showed that cases occurred more frequently than by random distribution in the months April to July, a $44 \%$ occurrence rate compared with the expected $33 \%$. However this difference is not statistically significant by the method of David and Newell (1965).

SIDE INVOLVED The left side (considering only the eye first affected) was involved in $60 \%$ of the whole series. This side difference was entirely due to the males, where the left side was involved in $75 \%$ as opposed to $52 \%$ in the females. However these differences are not significant at the $5 \%$ level.

FUNDAL APPEARANCES Descriptions of minor fundal changes are so subjective that no valid comparison of findings by different observers is possible. We therefore confined our analysis to observations of haemorrhage, papilloedema, and blurring or pallor of the disc (Table III). In the whole series of 78 eyes affected (unilateral and simultaneous bilateral) $17 \%$ had papilloedema or blurred discs with haemorrhage (the most objective changes), and a further $24 \%$ had blurred discs only-a total of $41 \%$ with possible swelling of the disc. The percentage of oedematous discs was the same in each eye. The age
TABLE III

FUNDAL APPEARANCE IN THE INITIAL ATTACK OF OPTIC NEURITIS IN 73 CASES (INCLUDING FIVE SIMULTANEOUS BILATERAL CASES, i.e., 78 EYES)

\begin{tabular}{lrrr} 
Disc Appearance & Male & Female & $\begin{array}{c}\text { Total } \\
\text { No. }\end{array}$ \\
\hline Papilloedema t haemorrhages & 6 & 4 & 10 \\
Blurred disc + haemorrhages & 2 & 1 & 3 \\
Blurred disc alone & 9 & 10 & 19 \\
Normal & 11 & 32 & 43 \\
Pale disc & 2 & 1 & 3 \\
Totals & 30 & 48 & 78
\end{tabular}

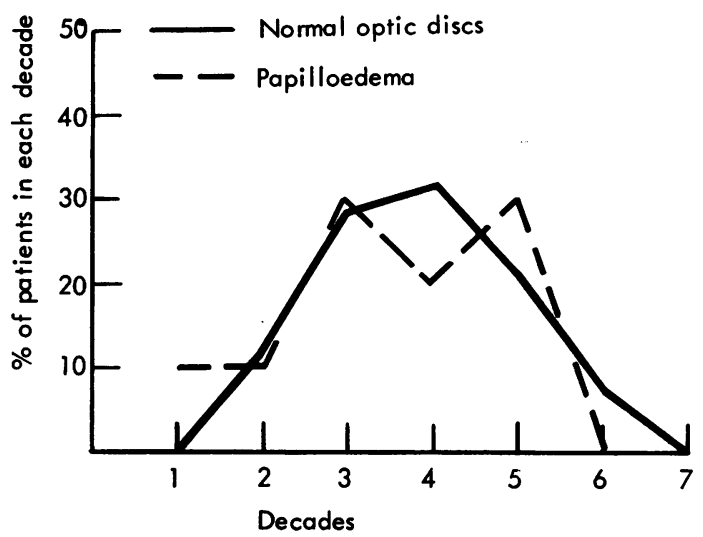

FIG. 2. Age structure of cases with papilloedema and with normal discs in the whole series of 73 cases.

spectrum was the same in those with papilloedema and those with normal discs (Fig. 2).

PAIN Over two-thirds of the whole series, 53 of 78 cases, had pain in and around the affected eye at some time in relation to the optic neuritis. Pain began most commonly at the same time as the blurred vision (Fig. 3), and in only $19 \%$ did it precede the optic neuritis by more than a week. The time of onset of the pain was the same in all subgroups. Pain occurred with equal frequency in patients of different ages, in the left and the right eye, and in males and females. It was no more frequent in those whose visual acuity sunk lowest, than in those whose sight was only slightly affected. It was slightly more common in those with abnormal discs $(78 \%)$ than in those with normal ones $(60 \%)$ but this difference was not statistically significant.

VISUAL ACUITY We have based our assessment on visual acuity as measured by Snellen and Jaeger reading types. By normal vision we mean corrected acuity of Snellen $6 / 6$ or $6 / 9$ with reading of Jaeger 


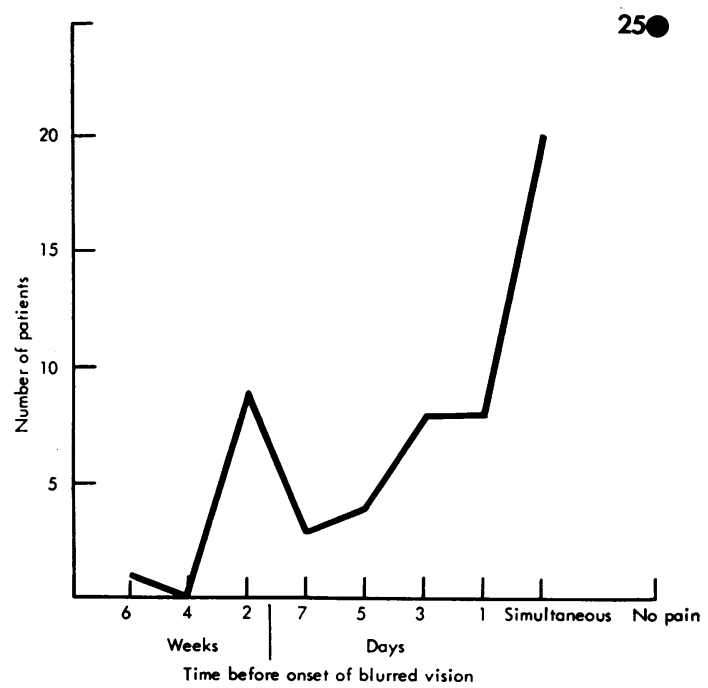

FIG. 3. Frequency distribution of the interval between the onset of pain and blurred vision in 73 cases (five simultaneous bilateral cases, i.e., 78 eyes).

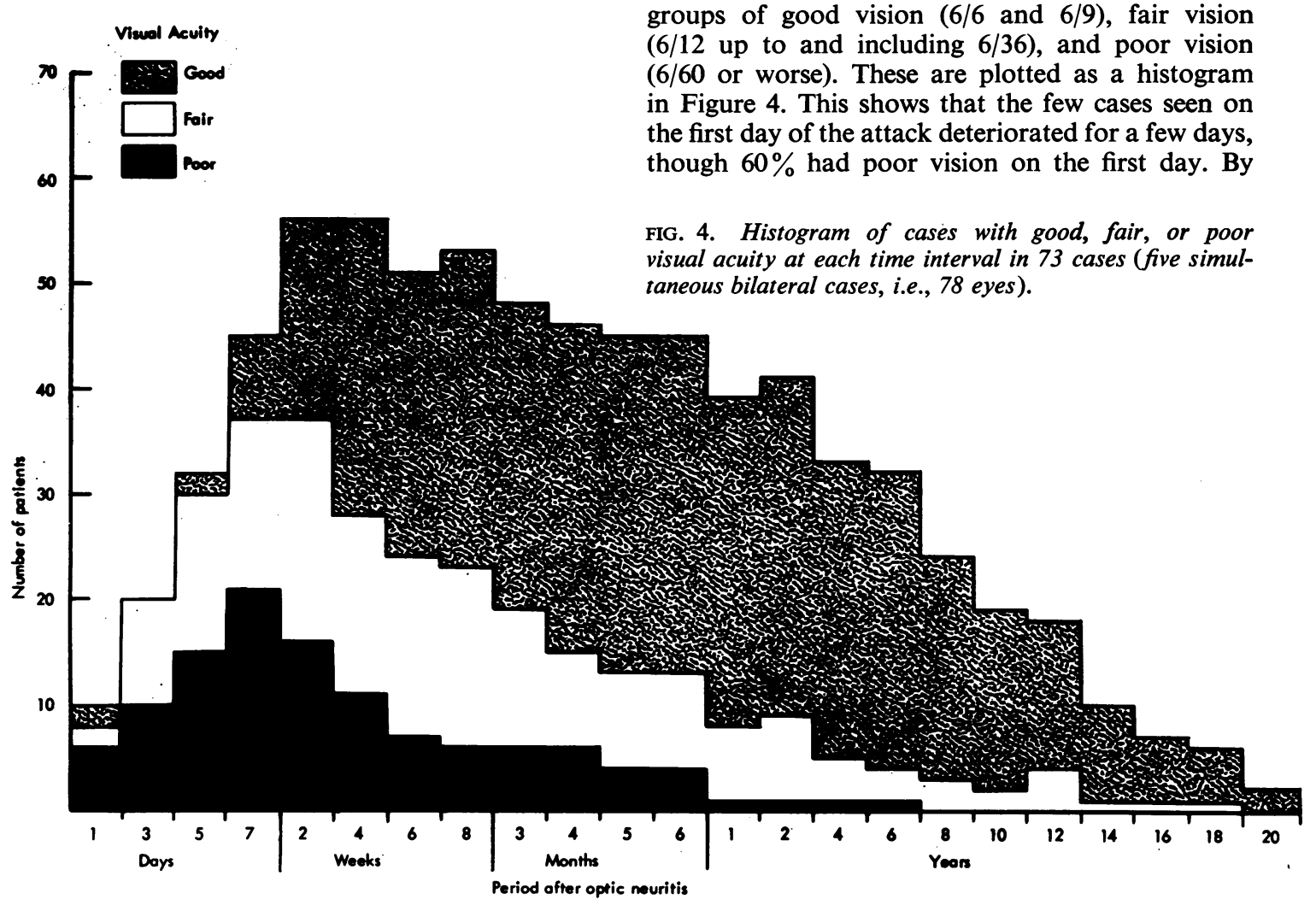

type 1 or 2 . Scotomata, if present, have not affected this degree of acuity. Data on the visual acuity at some time during the attack of optic neuritis was available in 71 of the 73 cases. In order to maintain a homogeneous population, acuities following all recurrent attacks of blurred vision were excluded. For studying the factors affecting the return of vision, a method has been devised for plotting acuity as a continuum related to time. The assumption has been made, and is supported by the figures we have, that the acuity changes in a linear fashion between two measurements. Thus, if the acuity was $6 / 18$ two weeks after the onset of the attack, and $6 / 9$ four weeks later, by interpolation the acuity four weeks after the onset of the attack will be 6/12 . This assumption is only warranted if the number of points for interpolation, and the difference between the two measured acuities are small. Thus, if the acuity was $6 / 60$ five days after the attack and $6 / 6$ six months later, interpolation is impossible, and the measured acuities alone have been used. Measured and interpolated acuities after the attack have been summated at times which are arbitrary, but based on the times for which known measurements are most available, and collected into three groups of good vision (6/6 and 6/9), fair vision (6/12 up to and including 6/36), and poor vision (6/60 or worse). These are plotted as a histogram in Figure 4. This shows that the few cases seen on the first day of the attack deteriorated for a few days, though $60 \%$ had poor vision on the first day. By

FIG. 4. Histogram of cases with good, fair, or poor visual acuity at each time interval in 73 cases (five simultaneous bilateral cases, i.e., 78 eyes). 

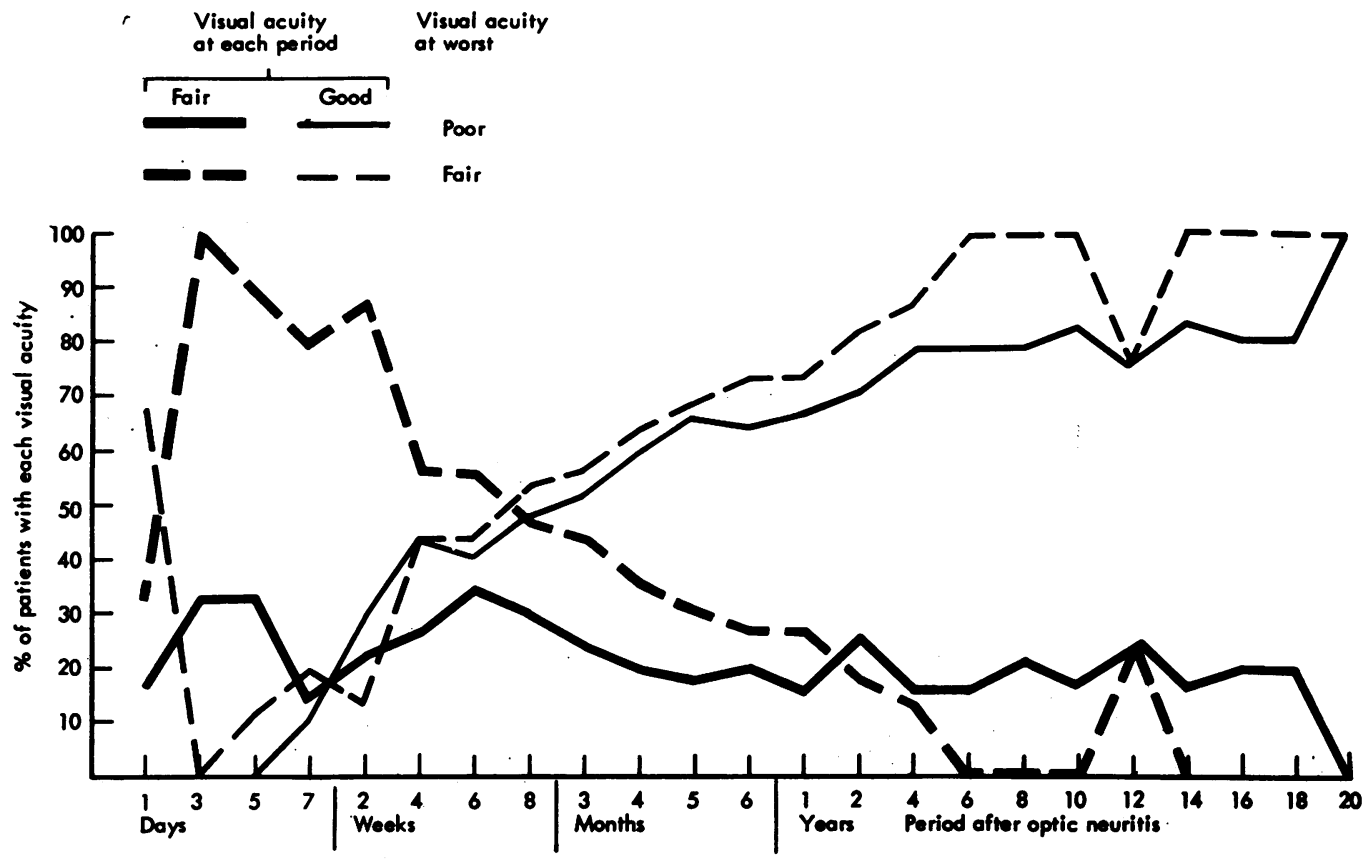

Fig. 5. Graph of visual acuity related to time. Continuous lines represent patients whose vision during the attack was poor (6/60 or less): interrupted lines, those whose vision in the attack was fair $(6 / 12$ to 6/36). In both groups thick lines represent fair acuity at the interval of measurement and thin lines good acuity.

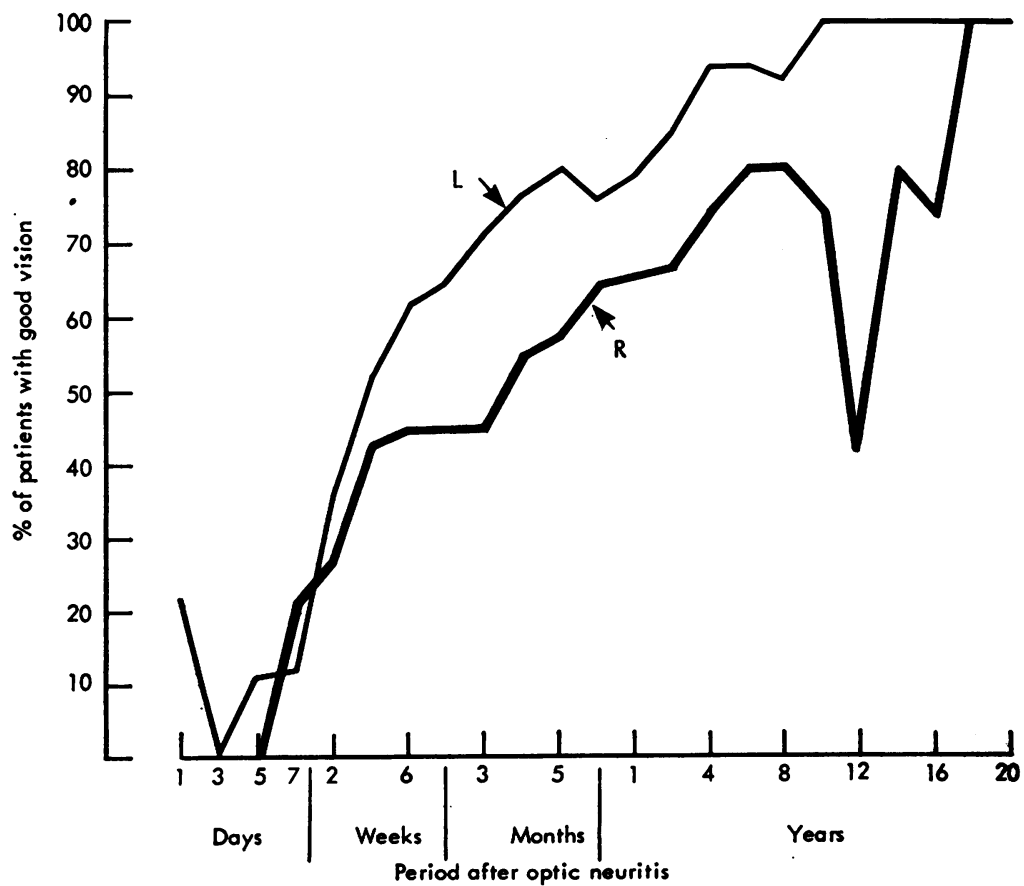

Fig. 6. Percentage of cases with good vision related to side affected. Data from 78 eyes. 
the end of the first week, vision was improving, though $40 \%$ still had poor and another $40 \%$ only fair vision. By a month, vision had returned to normal in half the patients, and by six months it was normal in three-quarters of them. Thereafter there was a slow but steady improvement in those with impaired acuity. Unilateral and bilateral optic neuritis showed similar curves; and neither sex, nor the occurrence of pain, nor papilloedema had any effect. It is important to note that there is no evidence that papilloedema carries a worse prognosis for vision.

The return of vision was only slightly worse (as shown by a slower recovery and final lessened acuity) in the group whose visual acuity at its lowest was $6 / 60$ or below, compared with those whose lowest acuity was $6 / 18$ to $6 / 36$ (Fig. 5). The acuity changes were not affected by age of onset, except that acuity was slightly slower in recovery after $\mathbf{5 0}$. Right-sided attacks seemed to have a slightly poorer prognosis (Fig. 6). At the time of the follow-up examination $27 \%$ still had evidence of scotomata. In most patients this was simply an area of relative dimness: and in two-thirds of them visual acuity was normal.

SINUSITIS Skull or sinus radiographs at the time of the attack of optic neuritis were available in $\mathbf{4 3}$ cases. Twelve $(28 \%)$ were reported as showing a sinus abnormality such as opacity of one or other sinus, mucosal thickening, or a fluid level. By comparison only one of a random series of 50 skull radiographs on epileptics admitted to the Department was reported as showing sinus abnormalities.

Of 44 patients questioned at the follow-up examination, $11(25 \%)$ gave a history of sinusitis at some time, 33 denied it: while of 132 unselected neurological outpatients questioned, $29(22 \%)$ gave such a history.

Neither a history nor radiographic evidence of sinusitis appeared to affect the incidence or severity of changes in visual acuity, nor the proportion having normal or abnormal optic discs.

\section{DISCUSSION}

After reviewing the records of 123 cases diagnosed as optic neuritis we rejected 50 on the grounds of insufficient diagnostic information or failure to fulfil our definition of optic neuritis given earlier. We were thus left with a homogeneous group of 73 cases for further analysis.

Of the cases rejected, six conformed to our definition except that their visual field defect was atypical. This figure is similar to the $4 \%$ of atypical field defects found by Chamlin (1953), who included these as optic neuritis in his series. If acute optic neuritis is in fact a single aetiological entity our six cases should probably be included. The argument for making a particular type of field defect essential for the diagnosis is weakened by the number of known causes for central scotomatous defects which have been described. Macular and retinal lesions, inflammation of the optic nerve due to syphilis and sinusitis, mechanical lesions of the chiasm and raised intracranial pressure, demyelinization, extrinsic poisons, metabolic diseases, vitamin deficiencies, and allergic conditions, together with hereditary optic atrophy, have all been reported to cause such scotomata (Watkins, 1939; Walsh and Ford, 1940; Kennedy and Carroll, 1960; Kelly, 1962; Joseph and Berkman, 1965; McAlpine et al., 1965; Björkenheim, 1966).

In addition to our six cases with atypical fields, a further six did not have visual fields charted and were also rejected. Separate analysis of the visual acuity in these 12 patients revealed findings, in the acute attack and on follow-up, similar to those in the homogeneous group of 73. This casts doubt on the necessity for a particular type of field defect in the clinical diagnosis of the condition. It seems probable that all 12 of our excluded cases would have been included in the series of Chamlin (1953) and of Hyllested and Møller (1961). However, fewer with atypical field defects later developed multiple sclerosis (Bradley and Whitty, 1967), which suggests that 'acute optic neuritis' is of mixed aetiology.

In the present series females constitute $63 \%$ of all cases, a figure similar to the $65 \%$ found by Adie (1932), the $68 \%$ by Leibowitz, Alter, and Halpern (1966), and the $62 \%$ by Hyllested and Møller (1961). However, Benedict (1942) had only $48 \%$ of females in his series and Marshall (1950) $47 \%$. The age distribution was similar in the present series to that found by previous authors.

Taub and Rucker (1954) found that cases occurred less frequently in the months November to March inclusive. In the present series a similar preponderance is noted between April and July. In neither series was the relationship statistically significant, but by combining the figures from both it becomes so at the $1 \%$ level (V6 = 3.38; David and Newell, 1965). The seasonal incidence of diseases supposedly due to virus infection has long been of interest, and recently Lee (1962) has drawn attention to it in leukaemia: and has pointed out that internal changes, such as hormonal levels, may also operate within this seasonal factor.

Lynn (1959) referred to the difficulty in establishing objective criteria of fundal appearance, and cast doubts on reports of differing proportions of fundal 
oedema in optic neuritis. Thus, she found all her patients had some abnormalities of the discs, while Adie (1932) found abnormalities in nearly a third. Blurred discs were found in $9 \%$ by Benedict (1942), in $8 \%$ by Sachs and Friedman (1922), and in $7 \%$ by Adie (1932). Measurable papilloedema is perhaps less subject to error, and was once thought to be rare in optic neuritis. However, the percentage of papilloedema in large series of cases ranges from 2 to 19 (Adie, 1932; Marshall, 1950; Schlossman and Phillips, 1954; Taub and Rucker, 1954; Hyllested and Møller, 1961) and in the present series it was 13. In children, Kennedy and Carroll (1960) found that $73 \%$ had 'papillitis'. This would include papilloedema and blurred discs, a combination for which our figure was $41 \%$.

The mechanism of the disc changes is not clearly established. Rosenfeld (1904) invoked an anatomical factor and suggested that changes such as demyelinization immediately behind the globe might cause papilloedema while similar changes retroorbitally would not. Brain (1934) supported this view. Swelling of the nerve at the optic foramen might certainly be expected to produce secondary compression and engorgement. However, Gartner (1953), from pathological studies, has cast doubts on this. In our cases the fundal appearances tended to be similar in the two eyes when bilateral neuritis occurred, either simultaneously or separately. This could be explained either by a similarity in point of attack in each eye, or by some individual factor in intraorbital anatomy which caused disc changes to appear in one person and not in another, in response to the common insult of optic neuritis. However, if the stereotyped picture of optic neuritis as defined is not considered due to a common cause, then variation of cause could account for variation of disc changes. It is worth emphasizing that our figures lend no support to the view suggested by Walsh (1957) that the presence of papilloedema, blurred discs, or haemorrhage carries a worse prognosis for visual recovery.

The cause of pain in optic neuritis is not known. It seems likely to be related to involvement of painsensitive structures in the optic nerve, the globe, or other intraorbital structures, since eye movement and pressure aggravate it. The presence of pain does not indicate a more extensive lesion since it showed no correlation with changes in visual acuity. The increased frequency of oedematous discs in those with pain may indicate that it is related to engorgement and tension in the optic nerve bundle. Pain was reported more frequently in the present series (68\%) than by Marshall (1950) who found it in only $35 \%$ of his cases and by Benedict (1942) who found it in half of his.
Our findings suggest that the ultimate prognosis for vision is good. By a month after the attack half the cases, and by six months three-quarters, have normal vision again. Surprisingly, the depth to which visual acuity sinks in the attack has only a small effect on this favourable prognosis (see Fig. 5). Hyllested and Møller (1961) obtained similar results. They found that $76 \%$ of their 52 cases 'recovered' within 14 days, and $14 \%$ had not remitted by 90 days; though exact visual acuities are not stated. However, our results are not strictly comparable with other series since we have excluded all measurements of visual acuity following recurrent attacks, and have assessed recovery in relation to time after attack. Previous authors in discussing improvement of vision have not segregated results in single and recurrent attacks, and have combined figures for visual acuities measured at varying and often unstated times from six months to 10 years after attacks. Since we have evidence that acuity may continue to improve over long periods, assessment from such combined figures may be misleading.

Lynn (1959) produced evidence that the age at onset of the attack affects recovery of vision. Assessing acuity six to 10 years after the attack in 200 cases she found that in those under 30 years of age at the time of attack $70 \%$ had good vision, while this was true of only $54 \%$ of those over 30 . In the present series, the prognosis was slightly worse in the over-50-year-old group but, apart from this, youth had no effect. Lynn (1959) also noted that acuity reached a maximum in the period from six to 10 years after an attack, being worse both before and after this. This may have been due to inclusion of those with recurrent attacks, for there is no evidence of a later worsening of acuity in the present series.

Wybar (1952) found complete colour blindness in 11 of his 25 cases of optic neuritis, up to 20 years after the initial attack; a further five had some impairment of colour vision. Lynn (1959) found bilateral red/green defects in 61 of 129 cases with a history of unilateral attacks. Several patients in the present series commented that everything still looked grey and colourless to the affected eye, but formal colour vision testing was not done. The proportion with residual scotomata in this series $(27 \%)$ is less than the $40 \%$ found by Hyllested and Møller (1961) and the $61 \%$ of Wybar (1952). The follow-up period was similar in all the studies.

The relationship of paranasal sinusitis to optic neuritis has caused much debate in the past. Brain (1934) cast doubts upon a causative relationship. However, the frequency of reported radiographic evidence of sinus abnormalities in our series $(28 \%)$ is surprising. It may be related to the particular 
attention of radiologists engendered by this debate. A controlled trial of radiographs reported 'blind' would be required to elucidate the point.

Bilateral attacks of optic neuritis occurred in $29 \%$ of our cases. The whole subject of bilateral optic neuritis has been reviewed recently by Hierons and Lyle (1959). Estimates of its frequency range from that of Adie (1932), who found only one case in the series of 70, to that of Schlossman and Phillips (1954) who recorded $46 \%$. Bilateral attacks may be more common in children (Brain, 1934; Meadows, 1954; Kennedy and Carroll, 1960). Marshall (1950) found that males had bilateral attacks more frequently than females but again this was not confirmed in the present series.

It would be interesting to know if cerebrospinal fluid abnormalities had any prognostic significance for recovery of visual acuity. The fluid is reported as abnormal in from $15 \%$ (Carroll, 1952) to $33 \%$ in the present series (Table IV). No views have been expressed by others on this point, and an insufficient number have been examined in our cases to provide an answer.

\section{TABLE IV}

FINDINGS IN CEREBROSPINAL FLUID IN 18 PATIENTS EXAMINED AT TIME OF ATTACK OF OPTIC NEURITIS

\begin{tabular}{lcccc}
$\begin{array}{l}\text { Cases } \\
\text { Examined }\end{array}$ & Abnormal & \multicolumn{2}{l}{ Abnormality } & \\
\cline { 2 - 5 } & $\begin{array}{l}\text { Raised } \\
\text { Protein }\end{array}$ & Lymphocytosis & $\begin{array}{l}\text { Paralytic } \\
\text { Lange } \\
\text { Curve }\end{array}$ \\
\hline 18 & 6 & 1 & 3 & 3
\end{tabular}

We conclude from this review that the prognosis for recovery of vision in acute optic neuritis is good. After one month $50 \%$ had normal vision and after six months $75 \%$. Of 41 examined two years after the attacks, vision was normal in $78 \%$, while at four years, of 33 examined $85 \%$ were normal: and there was evidence that improvement could continue for longer periods. The outlook was unaffected by fundal appearances, pain, bilateral incidence, or radiographic evidence of sinus abnormality in the acute attack, or by sex. In those over 50 , and, for no apparent reason, in those with attacks in the right eye recovery appeared to be worse.

\section{SUMMARY}

Seventy-three cases of acute optic neuritis seen in the Department of Neurology at Oxford from 1946 to 1966 are reviewed to provide information on the clinical features of the condition and on the prognosis for vision. Sixty-three per cent of cases were female and $37 \%$ male. Eighty-two per cent were between 20 and 50 years old at the time of the attack. The left eye was involved in $60 \%$ of unilateral cases-an unexplained finding. No significant difference in initial clinical features and course of attack was detected between those with unilateral or bilateral involvement. Cases tended to occur more frequently between April and July, a finding noted previously, but also unexplained.

Seventeen per cent of cases had papilloedema or haemorrhages in the affected eye, while a further $24 \%$ had a blurred optic disc. Pain around the affected eye occurred in $68 \%$.

The time of recovery of vision has been plotted for each patient. Recovery of normal vision occurred in half the cases within one month and in threequarters within six months of the onset. Prognosis was unaffected by fundal appearances, pain, unilateral or bilateral incidence, and the presence of radiographic evidence of sinus abnormality at the time of the attack, or by sex. It appeared to be worse in those over 50, and with attacks in the right eye.

Twenty-eight per cent of skull radiographs taken at the time of the attacks showed paranasal sinus abnormalities. Twenty-five per cent of this series and $22 \%$ of a controlled series of unselected neurological outpatients reported attacks of sinusitis in the past.

The authors wish to thank Professor Ritchie Russell and Dr. J. M. K. Spalding for allowing them to study patients under their care: Dr. D. J. Newell, Professor of Biostatistics in the University of Newcastle upon Tyne, for statistical help and for reading the manuscript: the Medical Illustration Department of the University of Newcastle upon Tyne for preparation of figures: and Miss Jenny Aspden for her meticulous tracing of patients for follow-up.

\section{REFERENCES}

Adie, W. J. (1932). The aetiology and symptomatology of disseminated sclerosis. Brit. med. J., 2, 997-1000.

Benedict, W. L. (1933). Retrobulbar neuritis and disease of the nasal accessory sinuses. Arch. Ophthal. (Chic.), 9, 893-904.

- (1942). Multiple sclerosis as an etiologic factor in retrobulbar neuritis. Ibid., 28, 988-995.

Björkenheim, B. (1966). Optic neuropathy caused by vitamin-B12 deficiency in carriers of the Diphyllobothrium lactum fish tapeworm, Lancet, 1, 688-690.

Bradley, W. G., and Whitty, C. W. M. (1967). In the press.

Brain, W. R. (1934). Some varieties of acute optic neuritis and retrobulbar neuritis. Trans. ophthal. Soc. U.K., 54, 221-229.

British Medical Journal (1965). 2, 606. Retrobulbar neuritis from monoamine-oxide inhibitors. (Leading article.)

Carroll, F.D.(1952). Optic neuritis: a 15-year study. Amer. J. Ophthal., 35, 75-82.

Chamlin, M. (1953). Visual field changes in optic neuritis. Arch. Ophthal., 50, 699-713.

David, H. A., and Newell, D. J. (1965). The identification of annual peak periods for a disease. Biometrics, 21, 645-650.

Gartner, S. (1953). Optic neuropathy in multiple sclerosis. Arch. Ophthal. 50, 718-724. 
Hierons, R., and Lyle, T. K. (1959). Bilateral retrobulbar optic neuritis. Brain, 82, 56-67.

Hyllested, K., and Møller, P. M. (1961). Follow-up on patients with a history of optic neuritis. Acta ophthal. (Kbh.), 39, 655-662.

Joseph, E., and Berkman, N. (1965). Complications oculaires dues aux inhibiteu de la mono-amine-oxydase. Presse méd.,73, 1627-1629.

Kelly, R. (1962). Lesions of the optic chiasm due to compression. Trans. ophthal. Soc. U.K., 82, 149-164.

Kennedy, C., and Carroll, F. D. (1960). Optic neuritis in children. Arch. Ophthal., 63, 747-755.

Kurland, L. T., Auth, T. L., Beebe, G. W., Kurtze, J. F., Lessell, S. Nagler, B., and Nefzger, M. D. (1963). Studies on the natural history of multiple sclerosis. Trans. Amer. neurol. Ass., 88, 231-2 and 233-5.

Lee, J. A. H. (1962). Seasonal variation in the clinical onset of leukaemia in young people. Brit. med.J., 1, 1737-1738.

Leibowitz, U., Alter, M., and Halpern, L. (1966). Clinical studies of multiple sclerosis in Israel. IV. Optic neuropathy and multiple sclerosis. Arch. Neurol. (Chic.), 14, 459-466.

Lynn, B. H. (1959). Retrobulbar neuritis. A survey of the present condition of cases occurring over the last 56 years. Trans. ophthal. Soc. U.K., 79, 701-716.

McAlpine, D., Lumsden, C. E., and Acheson, E. D. (1965). Multiple Sclerosis. A reappraisal. Livingstone, Edinburgh and London.

Marshall, D. (1950). Ocular manifestations of multiple sclerosis and relationship to retrobulbar neuritis. Trans. Amer. ophthal. Soc., 48, 487-525.
Meadows, S. P. (1954). Neuro-ophthalmological aspects of failure of vision in children. Proc. roy. Soc. Med., 47, 494-499.

Rosenfeld, M. (1904). Endarteriitis bei multipler Sklerose. Arch. Psychiat. Nervenkr., 38, 474-489. Quoted by Taylor, E. W. (1922). Multiple sclerosis: The location of lesions with respect to symptoms. In Multiple Sclerosis. Ass. Res. nerv. ment. Dis. 2, 179-197.

Sachs, B., and Friedman, E. D. (1922). The General symptomatology of multiple sclerosis Ibid. , 2, 49-67.

Schlossman, A., and Phillips, C. C. (1954). Optic neuritis in relation to demyelinating diseases. Amer. J. Ophthal., 37, 487-494.

Sugar, S. (1939). Papillitis and papilledema in multiple sclerosis. Amer J. Ophthal., 22, 135-139.

Taub, R. G., and Rucker, C. W. (1954). The relationship of retrobulbar neuritis to multiple sclerosis. Amer. J. Ophthal., 37, 494-497.

Walsh, F. B. (1957). Clinical Neuro-Ophthalmology, 2nd ed. Williams and Wilkins, Baltimore.

-, and Ford, F. R. (1940). Central scotomas. Their importance in topical diagnosis. Arch. Ophthal. (Chic.), 24, 500-532.

Watkins, A. L. (1939). The cerebrospinal fluid in cases of optic neuritis, 'toxic amblyopia' and tumours producing central scotomas. Arch. Neurol. Psychiat. (Chic.), 41, 418-421.

Woods, A. C., and Rowland, W. M. (1931). An etiologic study of a series of optic neuropathies. J. Amer. med. Ass., 97, 375-379.

Wybar, K. C. (1952). The ocular manifestations of disseminated sclerosis. Proc. roy. Soc. Med., 45, 31 5-319. 